\title{
Subcutaneous and visceral fat distribution and daily physical activity: comparison between young and middle aged women
}

\author{
T Abe, T Sakurai, J Kurata, Y Kawakami, T Fukunaga
}

\begin{abstract}
Objective-To examine the effects of aging and physical activity on distribution patterns in subcutaneous and visceral fat.

Methods-Distributions of subcutaneous fat mass at six segments (face and neck, forearm, upper arm, trunk, thigh, and lower leg) were determined by adipose tissue thickness measurements by $B$ mode ultrasonogram and body surface areas. Visceral fat mass was calculated by subtracting subcutaneous fat mass from the total fat mass determined hydrodensitometrically. Measurements were made on young and middle aged, trained and sedentary women (four groups).

Results-Per cent body fat was lower in trained than in sedentary individuals, both in the young and the middle aged subjects. The distribution of subcutaneous fat mass differed between sedentary and trained women. Trained young women had a reduced subcutaneous fat mass compared to sedentary young subjects in all segments except face and neck; the disparity between middle aged sedentary and trained women was limited to upper arm and trunk $(P<0.01$ each), with no significant difference in face and neck, forearm, and lower limb segments. Differences in visceral fat mass between sedentary and trained subjects were similar for young and middle aged women (young, $2.5 v 3.7$ $\mathrm{kg}$; middle aged, $4.0 v 6.5 \mathrm{~kg}$ ).

Conclusions-Women who exercise regularly appear to accumulate less adipose tissue, especially in upper arm and trunk segments as they get older, with visceral fat mass remaining lower than in sedentary individuals.

(Br f Sports Med 1996;30:297-300)
\end{abstract}

Key terms: visceral fat mass; subcutaneous fat mass; aging; physical activity

Aging is associated with changes in body composition. Cross sectional and longitudinal studies on aging and body composition have documented a decrease in fat-free mass due to aging. ${ }^{12}$ As body fat mass has shown to remain unchanged or to increase slightly, the percentage of body fat usually tends to increase in older individuals. The fat distribution pattern of older individuals is characterised by the accumulation of fat, especially in the abdominal region, ${ }^{3}$ which a number of studies have associated with metabolic complications such as glucose intolerance, hyperinsulinaemia, non-insulin-dependent diabetes, hypertension, and dyslipidaemia. ${ }^{4-6}$ These metabolic changes would contribute to augmented risk of cardiovascular diseases.

The increase in fat percentage with aging is partly related to a decrease in physical activity. While many previous reports have focused on body composition in older athletes, ${ }^{89}$ much is still unknown about the fat distribution characteristics. We thought it worthwhile, therefore, to study the fat distribution patterns and body composition of older individuals who exercise regularly and compare them to those of younger athletes.

In the present study we examined the effect of regular exercise and aging on body composition and fat distribution, especially with regard to the proportion of visceral and subcutaneous fat. For this purpose, we compared young and older women who exercised regularly to those with very low physical activity levels.

\section{Methods}

Ninety six women were divided into four groups. The sedentary groups consisted of 33 young and 24 premenopausal middle aged women, and the endurance trained groups consisted of 19 young and 20 premenopausal middle aged women. The young women ranged in age from 18 to 25 years and the middle aged women aged from 40 to 52 years. The volunteers provided their written consent for participation in the study. All the subjects were healthy and were screened for chronic diseases such as cardiovascular disease, hypertension, diabetes, other endocrine disorders, and drugs. The trained subjects exercised regularly for one to two hours per day for three to six days per week, doing aerobic exercise such as running, cycling, or dancing. The sedentary 
Table 1 Physical characteristics of healthy young and middle aged women. Values are mean (SD)

\begin{tabular}{|c|c|c|c|c|c|c|c|}
\hline & \multicolumn{3}{|l|}{ Young } & \multicolumn{3}{|l|}{ Middle aged } & \multirow[b]{2}{*}{$2 * 2 A N O V A^{1}$} \\
\hline & Sedentary & Trained & Diff & Sedentary & Trained & Diff & \\
\hline $\mathbf{n}$ & 33 & 19 & & 24 & 20 & & \\
\hline Age (years) & $19.2(0.8)$ & $19.3(1.0)$ & & $44.3(3.4)$ & $44.3(3.0)$ & & Age, $\mathrm{P}<0.001$ \\
\hline Height $(\mathrm{cm})$ & $160.2(5.5)$ & $159.6(5.7)$ & & $155.3(5.5)$ & $153.9(6.2)$ & & Age, $\mathrm{P}<0.001$ \\
\hline Body mass (kg) & $53.7(4.5)$ & $54.3(6.3)$ & & $55.2(6.4)$ & $50.4(4.2)$ & $t$ & Interaction, $\mathrm{P}<0.05$ \\
\hline Body mass index $\left(\mathrm{kg} \mathrm{m}^{-2}\right)$ & $20.9(1.1)$ & $21.3(1.6)$ & & $22.9(2.6)$ & $21.3(1.2)$ & $\star$ & $\begin{array}{l}\text { Age, } P<0.01 \\
\text { Interaction, } P<0.05\end{array}$ \\
\hline Body fat (\%) & $25.7(3.3)$ & $17.8(2.9)$ & $\dagger$ & $29.6(3.7)$ & $22.9(3.4)$ & $t$ & Age, Training, $P<0.001$ \\
\hline Total fat mass $(\mathrm{kg})$ & $13.8(2.0)$ & $9.8(2.3)$ & $\dagger$ & $16.5(3.5)$ & $11.6(2.3)$ & $t$ & Age, Training, $\mathrm{P}<0.001$ \\
\hline Fat-free mass (kg) & $39.9(4.0)$ & $44.5(4.7)$ & $t$ & $38.7(3.9)$ & $38.8(3.2)$ & & $\begin{array}{l}\text { Age, Training, } \mathrm{P}<0.01 \\
\text { Interaction, } \mathrm{P}<0.01\end{array}$ \\
\hline
\end{tabular}

Diff, within-group differences: ${ }^{\star} \mathrm{P}<0.05,+\mathrm{P}<0.01$.

${ }^{1} \mathrm{~A} 2 \star 2$ analysis of variance (ANOVA) was performed with age and training status as factors.

subjects engaged in exercise less than 60 minutes per day on two days per week.

DETERMINATION OF TOTAL BODY FAT MASS

Body density was measured by the hydrostatic weighing technique as described previously. ${ }^{10}$ Pulmonary residual volume was measured using the oxygen dilution method of Rahn et al. ${ }^{11}$ The mean of three measurements was used in the calculation of body fat percentage from body density, using Siri's equation. ${ }^{12}$ Total body fat mass was obtained by multiplying body fat percentage by body weight.

\section{DETERMINATION OF SUBCUTANEOUS AND} VISCERAL FAT MASS

Total mass of subcutaneous fat was calculated as the sum of subcutaneous fat mass of each of the body segments. This was estimated from the surface area and mean thickness of subcutaneous adipose tissue layers at (1) face and neck, (2) upper arm, (3) forearm, (4) thigh, (5) lower leg, and (6) trunk..$^{13}$ The whole body surface was sectioned into nine areas after Shintani. ${ }^{14}$ Scalp, hand, and foot segments were excluded from subcutaneous fat mass calculations because subcutaneous fat was too sparse at these sites.

Several sites were selected from each segment (except the forearm), covering the anterior and posterior areas, and the mean adipose tissue thicknesses of these sites represented the adipose tissue thickness of each segment. Six sites (juxta-umbilical, subscapular, suprailiac, mid-axillary, anterior chest, and sternum) were selected for measurement of the trunk, due to large variation of adipose tissue thickness over the trunk. Sites were precisely located and marked with a surgical pen before measurement. The measurements were made on the right side of each subject while she was standing upright. The 15 sites selected from the six body segments and the anatomical landmarks used to identify these sites in a reproducible manner were as described by Abe et al. ${ }^{15}$

Ultrasonographic evaluation of subcutaneous adipose tissue (including skin) was performed using a real time linear electronic scanner (SSD-500, Aloka). Precision and linearity of the-image reconstruction have been confirmed elsewhere. ${ }^{1617}$ The scanning head, with the water soluble transmission gel which provided acoustic contact without depression of the skin surface, was placed perpendicular to the tissue interface under the marked site. Distortion of tissues due to excess compression was eliminated by observing that no movement of tissues occurred in a real time ultrasonic image. Subcutaneous adipose tissue was measured directly from the screen using electronic calipers positioned at the skin and adipose tissue-muscle interfaces. ${ }^{10}$ Dermis thickness was excluded according to Tan et al. ${ }^{18}$ Body surface area was calculated using the equation of Nakamura ${ }^{19}$ :

Body surface area $\left(\mathrm{m}^{3}\right)=70.98 \times($ body mass $)^{0.425} \times(\text { height })^{0.725}$

The density of fat was taken as $900(\mathrm{~kg}$ $\left.\mathrm{m}^{-3}\right) .^{20}$ The proportion of fat in adipose tissue was considered to be 0.80 according to Baker $^{21}$ and Garrow. ${ }^{22}$

Visceral fat mass was calculated as the difference between total fat mass (total body fat mass) and subcutaneous fat mass (subcutaneous fat mass). We confirmed that the deviation in duplicate visceral fat mass and subcutaneous fat mass measurements was $2.5 \%$ and $5.0 \%$, respectively.

\section{STATISTICAL ANALYSES}

Means and standard deviations were calculated using standard statistical procedures. Statistical comparisons were made by a two way analysis of variance (ANOVA: factor $1=$ aging, factor $2=$ training status). The designated level of statistical significance was $P<0.05$.

\section{Results}

The physical characteristics of the subjects are shown in table 1 .

PERCENTAGE OF BODY FAT AND FAT-FREE MASS Body fat percentage was higher in middle aged women than in young women by $3.9 \%$ and $5.1 \%$ for sedentary and active subjects, respectively. The young and middle aged sedentary women had more body fat than their active counterparts by $7.9 \%$ and $6.7 \%$. In young subjects, fat-free mass was significantly greater in active than in sedentary women $(F=14.30, P$ $<0.01$ ); however, no significant difference in fat-free mass was observed between active and sedentary middle aged women $(F=0.01, P>$ 0.05). 
Table 2 Subcutaneous and visceral fat mass distributions in young and middle aged women. Values are mean (SD).

\begin{tabular}{|c|c|c|c|c|c|c|c|}
\hline & \multicolumn{3}{|l|}{ Young } & \multicolumn{3}{|l|}{ Middle aged } & \multirow[b]{2}{*}{$2 * 2 A N O V A^{1}$} \\
\hline & Sedentary & Trained & Diff & Sedentary & Trained & Diff & \\
\hline \multicolumn{8}{|c|}{ Subcutaneous fat mass $(\mathrm{kg})$} \\
\hline Face and neck & $0.29(0.05)$ & $0.26(0.05)$ & & $0.32(0.07)$ & $0.26(0.05)$ & t & Training, $\mathrm{P}<0.01$ \\
\hline Forearm & $0.40(0.08)$ & $0.33(0.08)$ & $t$ & $0.33(0.09)$ & $0.28(0.07)$ & & Age, Training, $P<0.001$ \\
\hline Upper arm & $0.90(0.20)$ & $0.64(0.15)$ & $t$ & $0.83(0.22)$ & $0.66(0.12)$ & t & Training, $P<0.001$ \\
\hline Trunk & $3.67(0.99)$ & $2.45(0.90)$ & $t$ & $4.20(1.46)$ & $2.75(0.75)$ & $t$ & Training, $P<0.001$ \\
\hline Thigh & $3.89(0.82)$ & $2.78(0.59)$ & $t$ & $3.45(1.21)$ & $2.89(0.53)$ & & Training, $\mathrm{P}<0.001$ \\
\hline Lower leg & $1.01(0.20)$ & $0.76(0.12)$ & $t$ & $0.82(0.22)$ & $0.73(0.13)$ & & Age, Training, $P<0.01$ \\
\hline Total & $10.13(1.81)$ & $7.22(1.64)$ & $t$ & $9.97(2.73)$ & $7.57(1.26)$ & $t$ & Training, $\mathrm{P}<0.001$ \\
\hline Visceral fat mass $(\mathrm{kg})$ & $3.66(1.17)$ & $2.53(1.23)$ & $t$ & $6.49(1.42)$ & $4.01(1.46)$ & $t$ & Age, Training, $\mathrm{P}<0.001$ \\
\hline
\end{tabular}

Diff, within-group differences; $\dagger \mathrm{P}<0.01$.

${ }^{1} \mathrm{~A} 2 \star 2$ analysis of variance (ANOVA) was performed with age and training status as factors.

VISCERAL FAT MASS AND SUBCUTANEOUS FAT DISTRIBUTION

Visceral fat mass was greater in trained and sedentary middle aged women than in young women of both groups (young: $\mathrm{F}=10.90, \mathrm{P}<$ 0.01 ; middle aged: $F=32.59, P<0.01$ ). Trained groups of young and middle aged women had less visceral fat than the sedentary group by $1.2 \mathrm{~kg}$ and $2.5 \mathrm{~kg}$, respectively, which indicates that the higher level of activity significantly affects visceral fat mass percentage in both young and middle aged women. Percentages of visceral fat mass with respect to total fat

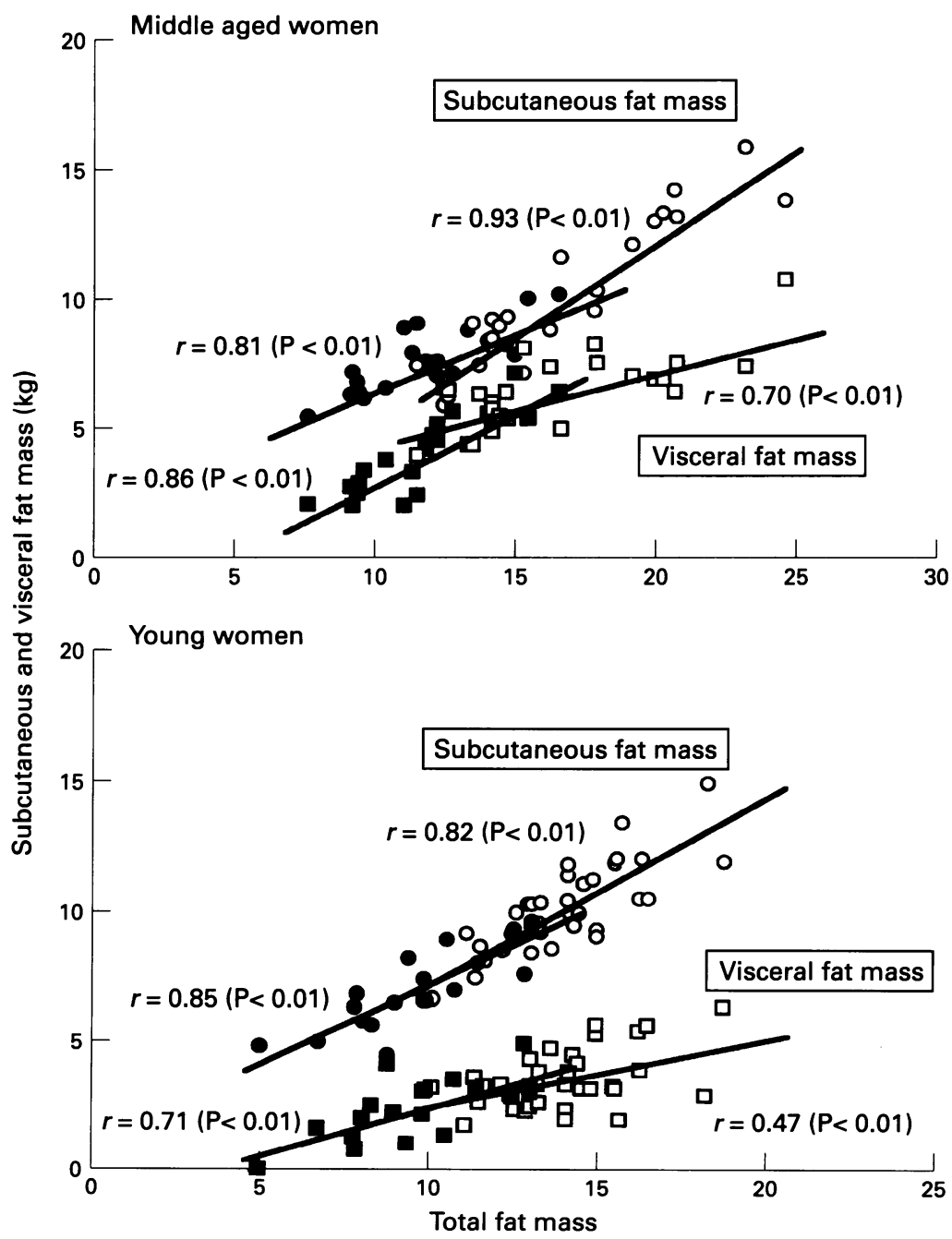

Figure 1 Relations between total body fat mass, visceral fat mass, and subcutaneous fat mass in young and middle aged women. Filled circles (subcutaneous fat mass) and squares (visceral fat mass), trained women; empty circles (subcutaneous fat mass) and squares (visceral fat mass), sedentary women. mass of active young, sedentary young, active middle aged, and sedentary middle aged women were $25.8 \%, 26.5 \%, 34.6 \%$, and 39.5 $\%$, respectively.

Active women had significantly lower subcutaneous fat mass than sedentary women in both age groups (young: $\mathrm{F}=33.18, \mathrm{P}<0.01$; middle aged: $\mathrm{F}=13.08, \mathrm{P}<0.01)$. Comparison of subcutaneous fat distribution revealed lower values in all areas for the active women than the sedentary subjects except for the face and neck. On the other hand, in middle aged women significant differences between active and sedentary subjects were noted only in face and neck, upper arm, and trunk segments.

The distributions of subcutaneous and visceral fat mass in the four subject groups are shown in table 2 .

RELATION BETWEEN TOTAL FAT MASS AND VISCERAL FAT MASS AND SUBCUTANEOUS FAT MASS

The figure illustrates the relations between total fat mass, visceral fat mass, and subcutaneous fat mass in young and middle aged women. In young women, significant positive correlations were observed between total fat mass $v$ visceral fat mass, and between total fat mass $v$ subcutaneous fat mass. The regression lines of trained and sedentary young women were similar. In middle aged women, significant positive correlations were also observed, but the regression lines for active and sedentary subjects did not coincide (that is, the sedentary subjects with greater fat mass had greater subcutaneous fat mass, while trained subjects who had less body fat mass tended to have a smaller percentage of visceral fat mass).

\section{Discussion}

The procedure used to measure subcutaneous and visceral fat mass is understood theoretically; however, it has yet to be determined whether it reflects the actual body fat mass. We previously studied the relation between body fat mass measured by magnetic resonance imaging and by the estimate used in this paper in young women subjects. ${ }^{15}$ The results showed a high correlation $(r=0.90)$ for subcutaneous adipose tissue area of the abdominal segment $v$ estimated subcutaneous fat mass, and a significant correlation of $r=0.78$ for the visceral adipose tissue area $v$ estimated visceral fat mass. 
Therefore, we believe that the estimation method of determining subcutaneous fat mass and visceral fat mass in our experiment is appropriately accurate for our purposes.

Our results show that exercising regularly decreases the body fat percentage of both young and middle aged women. However, middle aged women who exercised regularly clearly had a higher percentage of body fat than young women on similar exercise regimens. While it is known that aging increases body fat, the results suggest that physical exercise cannot fully suppress the increase in fat that results from aging. Kohrt $e t a l^{3}$ conducted a comparative study (of young and middle aged men and women, both active and sedentary) and reported that regular exercise suppressed the increase in body fat caused by aging. They also found that mature athletes had higher percentages of body fat than young athletes. Similar results have been reported by other researchers. $^{824}$

The fact that the visceral fat mass of sedentary middle aged women was $77 \%$ higher than that of sedentary young women confirms the increase in body fat caused by aging. The proportion of visceral fat mass with respect to total fat mass was $26.5 \%$ in young women and $39.3 \%$ in middle aged women. Borkan et $a l^{\beta}$ also noted the increase in visceral fat mass caused by aging. Our study showed that both young and middle aged women could decrease their visceral fat mass by maintaining a regular exercise regimen. While the visceral fat mass ratio of active young women was $25.8 \%$, similar to that in sedentary young women, in active middle aged women the ratio was $34.6 \%$, which is considerably lower than in sedentary middle aged women. These results are shows in the figure, which gives the relations between total fat mass and visceral fat mass in young and middle aged women. Very few studies have been conducted on the effects of exercise on visceral fat mass, ${ }^{25}$ and to our knowledge no studies have taken the effects of aging into consideration.

The active young women in our study had much lower subcutaneous fat mass in all segments than the sedentary young women. Between the middle aged groups, the only differences noted were in the upper arm and trunk sections. There was no significant difference in the lower body segments among the middle aged women. Despres et $a l^{26}$ reported that after 20 weeks of physical training skinfold thickness of the trunk decreased by $22 \%$. The limb segments decreased by $12 \%$, comparatively less than the trunk. Other studies also concluded that trunk fat mass responded to physical exercise by decreasing faster than the limb segment fat mass. All these results confirm our findings.

In conclusion, physical conditioning was effective both in young and middle aged women in reducing subcutaneous fat in the upper body, and in reducing visceral fat. Fat accumulation in the abdominal section has been shown to be closely related to the risk factors for arteriosclerosis. Physical exercise, especially in middle aged women, would contribute significantly to lowering these risk factors through reduction of fat in the upper body regions.

1 Forbes GB, Reina JC. Adult lean body mass declines with age: some longitudinal observations. Metabolism 1970;19:653-63.

2 Novak LP. Aging, total body potassium, fat-free mass, and cell mass in males and females between 18 and 85 years. $\mathcal{F}$ Gerontol 1972;27:438-43.

3 Borkan GA, Hults DE, Gerzof SG, Robbins AH, Silbert CK. Age changes in body composition revealed by computed tomography. $\mathcal{F}$ Gerontol 1983;38:673-7.

4 Bjorntorp P. Abdominal obesity and the development of non-insulin dependent diabetes mellitus. Diabetes Metab non-insulin dependent

5 Despres JP, Moorjani S, Lupien PJ, Tremblay A, Nadeau A, Bouchard C. Regional distribution of body fat, plasma lipoproteins, and cardiovascular disease. Arteriosclerosis 1990;10:497-511.

6 Kissebah AH, Peiris AN. Biology of regional body fat distribution: relationship to noninsulin-dependent diabetes mellitus. Diabetes Metab Rev 1989;5:83-109.

7 Shephard RJ. Assessment of physical activity and energy neeeds. Am f Clin Nutr 1989;50(suppl):1 195-200.

8 Coggan AR, Spina RJ, Rogers MA. Histochemical and enzymatic characteristics of skeletal muscle in master enzymatic characteristics of skeletal musc
athletes. F Appl Physiol 1990;68:1896-901.

9 Pollock ML, Foster C, Knapp D, Rod JL, Schmidt DH. Effect of age and training on aerobic capacity and body composition of master athletes. F Appl Physiol 1987;62: 725-31.

10 Abe T, Kondo M, Kawakami Y, Fukunaga T. Prediction equations for body composition of Japanese adults by B-mode ultrasound. Am F Hum Biol 1994;6:161-70.

11 Rahn H, Fenn WO, Otis AB. Daily variations of vital capacity, residual air, expiratory reserve including a study of the residual air method. $\mathcal{A}$ Appl Physiol 1949;1:725-36.

12 Siri WE. Body composition from fluid spaces and density. In: Brozek J, Henschel A, eds. Techniques for measuring body composition. Washington DC: National Academy of Scicomposition. Washington.

13 Hattori K, Numata N, Ikoma M, Matsuzaka A, Danielson RR. Sex differences in the distribution of subcutaneous and RR. Sex differences in the distribution
internal fat. Hum Biol 1991;63:53-63.

14 Shintani J. On the surface area of Japanese. 3. Age difference of regional area and ratio. Kokumin Eisei 1931;8:440-60 (in Japanese).

15 Abe T, Kawakami Y, Sugita M, Yoshikawa K, Fukunaga T. Use of B-mode ultrasound for visceral fat mass evaluation: comparisons with magnetic resonance imaging. Appl Hum Sci 1995;14:133-9.

16 Kawakami Y, Abe T, Fukunaga T. Muscle-fiber pennation angles are greater in hypertrophied than in normal muscles. f Appl Physiol 1993;74:2740-44.

17 Eston R, Evans R, Fu F. Estimation of body composition in Chinese and British men by ultrasonographic assessment of segmental adipose tissue volume. Br $¥$ Sports Med 1994; of segmental

18 Tan CY, Statham B, Marks R, Payne PA. Skin thickness measurement by pulsed ultrasound: its reproducibility, validation and variability. Br $\mathcal{F}$ Dermatol 1982;106:657-67.

19 Nakamura T. Study on the body surface area of Japanese. 7. On the surface area and estimating equation for the women between 20 and 40 years old. Nagasaki Sohgo Kohshu Eiseigaku Zasshi 1959;8:246-59 (in Japanese).

20 Fidanza F, Keys A, Anderson JT. Density of body fat in man and other animals. F Appl Physiol 1953;6:252-6.

21 Baker GL. Human adipose tissue and age. Am 7 Clin Nutr 1969;22:829-35.

22 Garrow JS. Energy balance and obesity in man, 2nd ed. Amsterdam: North Holland Publishing Co, 1978.

23 Kohrt WM, Malley MT, Dalsky GP, Holloszy JO. Body composition of healthy sedentary and training, young and older men and women. Med Sci Sports Exerc 1992;24:832-

24 Poehlman ET, Melby CL, Badylak SF. Relation of age and physical exercise status on metabolic rate in younger and older healthy men. $\mathcal{f}$ Gerontol 1991;46:B54-8.

25 Despres JP, Pouliot MC, Moorjani S, Nadeau A, Tremblay A, Lupien PJ, et al. Loss of abdominal fat and metabolic response to exercise training in obese women. Am 7 Physiol 1991;261:E159-67.

26 Despres JP, Bouchard C, Tremblay A, Savard R, Marcotte $M$. Effects of aerobic training on fat distribution in male subjects. Med Sci Sports Exerc 1985;17:113-8. 